U.IMR, Volume 6 Number 2, December, 2021, pp 142 - 148

ISSN: 2616 - 0668

https://doi.org/10.47430/ujmr.2162.020

Received: $3^{\text {rd }}$ December, 2021 Accepted: $31^{\text {st }}$ December, 2021

\title{
Evaluation of Hepatitis B vaccine Immunogenicity in Relation to ABO and Rhesus Blood Group in vaccinated subjects in Bauchi State, Nigeria
}

\author{
${ }^{* 1}$ Thomas, K.M. (D), ${ }^{2}$ Zakari, H., ${ }^{3}$ Lar, P.M., ${ }^{4}$ Vem, T.S. \\ ${ }^{1}$ Department of Microbiology and Immunology, University of Jos, Plateau State, Nigeria \\ ${ }^{2}$ Department of Microbiology, University of Jos, Plateau State, Nigeria \\ ${ }^{3}$ Department of Microbiology, University of Jos, Plateau State, Nigeria \\ ${ }^{4}$ Department of Medical Laboratory Sciences, University of Jos, Plateau State Nigeria \\ Corresponding Author: kyautathomas@ymail.com; +2347036181047
}

\begin{abstract}
Hepatitis B virus infection is a global public health issue. It can result in hepatocellular carcinoma (HCC), and liver cirrhosis when not properly managed. The discovery of Hepatitis B vaccine and its incorporation into immunization programmes has brought a drastic decline in the incidence of both chronic and acute hepatitis B. However, this achievement is being confronted by cases of vaccine sub-optimal immune response, non-responsiveness and breakthrough infection which may be associated with the host's genetic predisposition such as; $A B O / R$ hesus blood groups and hemoglobin genotype. The study aimed at investigating hepatitis B vaccines responsiveness (immunogenicity) and its association with the hosts' $\mathrm{ABO}$ and Rhesus blood group among vaccinated subjects in Bauchi State Nigeria. This was a cross-sectional investigation comprising of 352 subjects of both sexes from age 1 year to 60 years. Out of the 352 subjects, 196 were vaccinated while 156 were unvaccinated. $5 \mathrm{~mL}$ of blood samples were collected and analyzed for determination of both $A B O$ and Rhesus blood group while the plasma part of the samples was tested for anti-HBs antibodies by enzyme linked immunosorbent assay (ELISA). The results revealed that $96(49.0 \%)$ of the vaccinated subjects had anti-HBs level $\geq 10 \mathrm{IU} / \mathrm{L}, 65(33.2 \%)$ had $\leq$ $10 \mathrm{IU} / \mathrm{L}$ and $35(17.9 \%)$ were non-responders while $26(16.7 \%)$ of the unvaccinated subjects had anti-HBs level $\geq 10 \mathrm{IU} / \mathrm{L}(P=0.003)$. On the relationship between the $A B O /$ Rhesus group and vaccine immunogenicity, blood group $A B$ had $100 \%$ sub-optimal response while group $B$ had $34.2 \%$ suboptimal response and $21 \%$ non-responders. Blood group $A$ and $O$ had the highest $\geq 10 \mathrm{IU} / \mathrm{L}$ anti$\mathrm{HBs}$ protective level of $52.8 \%$ and $50.0 \%$ respectively. However, there was no significant association between HBV vaccine responsiveness and hosts' $A B O /$ Rhesus. The protective rate against HBV infection was moderate. Nevertheless, some blood types had higher responses than others. Therefore, a considerable proportion of vaccinated persons should be considered for either booster doses or revaccination.

Keywords: ABO; Hepatitis B Virus; Rhesus blood group; Vaccine Immunogenicity.
\end{abstract}

INTRODUCTION

Hepatitis B virus infection has been identified as one of the public health challenges that causes approximately 0.5 million to 1.2 million deaths annually following complications as a result of hepatocellular carcinoma, cirrhosis and chronic hepatitis (Zenebe et al., 2014, Graber-Stiehi, 2018). According to the World Health Organization (2017) report, it was revealed that WHO Western pacific Region recorded the highest number of individuals living with active positive cases of hepatitis B virus. This case was estimated to be $6.2 \%$ which is approximately over 100 million cases (Magaji, et al., 2021). Whereas in the African Region, there is an estimate of 60 million cases (6.1\%). These two Regions together account for $68 \%$ of the world's hepatitis B cases (WHO 2017). The non-vaccinated group is considered one of the highest risk groups that are more susceptible to the disease. They are often vulnerable to hepatitis $B$ infection on exposure to contaminated blood and or blood products (Fuad, et al., 2017). In Nigeria, a national prevalent rate of $12.2 \%$ has been reported (Adebola, et al., 2016).

Vaccination still remains the primary most effective baseline action in HBV infection prevention and control (Wiedermann, et al., 2016). WHO has recommended that the HBV vaccine should be incorporated into the infant immunization program of every country (Gunasekaran and Sree, 2018). It has been reported that the vaccine has brought about a significant decrease in the rate of the infection. However, even with the introduction of the HBV vaccine in Nigeria since 2004, there seems to be cases of suboptimal and non- 
UJMR, Volume 6 Number 2, December, 2021, pp 142 - $148 \quad$ ISSN: 2616 - 0668

response to the vaccine by the vaccinated individuals (Damulak, et al., 2013). Different factors have been suggested to be responsible for the vaccine failure. These factors range from Human Leukocyte Antigen polymorphism (HLA), vaccine factor, dose schedule and sex of the host, (Sadoh, and Ofili, 2014). Other scholars have argued that $S$ gene-related mutants may be responsible for the nonresponsiveness (Chang, 2010, Qin, and Liao, 2018).

The associations between the $\mathrm{ABO} /$ Rhesus blood groups and vaccine failure have not been given much attention, unlike the association between $\mathrm{ABO} /$ Rhesus and diseases which has been studied since the early 1900s (Abegaz, 2021). However, because of the absence of some blood group antigens, there have been scientific arguments and counter arguments on the relationships between vaccine failure and $A B O$ blood group (Fan, et al., 2020). According to the theory of human genetic, infectious diseases, variation of inherence variants can influence any foreign body inoculated in the human body (Casanova, 2015). This implies that introduction of vaccine inoculum in the human body can be influenced. Cooling (2015), also came up with a suggestion and argued that; "Blood groups determine host immunogenicity to vaccine." Therefore, these two theories and other related theories that might possibly exist point to the possibility of genetic predisposition such as; $\mathrm{ABO} /$ Rhesus blood groups being capable of influencing Hepatitis $B$ vaccine immunogenicity. The four major $A B O$ blood groups include; type $A, B, A B$ and $O$.

The antigens of the blood group are expression of inherited polymorphic traits in a population (Wang, et al., 2012). Variation in hosts' blood group antigens has been associated with their susceptibility to antigens. Similarly, in terms of intracellular ingestion, $\mathrm{ABO} /$ Rhesus antigens ease the process of adherence via micro domains membrane (Gunasekaran and Sree, 2018). Respective types of blood can cause transformation in congenital immune response. There is an overrepresentation in the populace domiciled in malaria endemic region by respective phenotypes related to quantity of malaria resistance by host. Antibodies against $\mathrm{ABO} /$ Rhesus, blood types, Kell and $\mathrm{T}$ can be provoked by microorganisms, (Cooling, 2015).

An overview of some literature has lots of evidence that point to many factors that might influence vaccine immunogenicity. Some of these factors have been proven to have a relationship with the HBV vaccine response, while others have no validated evidence. Host genetic factors such as HLA have been investigated and found to influence HBV vaccine response. However, host genetic predispositions such as; $\mathrm{ABO}$ and Rhesus blood groups have not been given attention. There is therefore the need to evaluate hepatitis B vaccine immunogenicity in relation to ABO/Rhesus Blood Group in Bauchi State, Nigeria.

\section{MATERIALS AND METHODS \\ Study Area}

This study was carried out within the Bauchi metropolis which is the capital city of Bauchi State. Bauchi State is one of the 36 States in Nigeria and is located in the north eastern part of the country. The State is made up of twenty (20) Local Government Areas with a population estimate of 5.6 million. However, the estimated population of the metropolis is 1,500,000 (National Population Census, 2006). It has land mass of approximately $49,119 \mathrm{~km}$ square area, representing about $5.3 \%$ of Nigeria's total land mass and is located between latitudes $9^{\circ} 3^{\prime}$ and $12^{\circ} 3^{\prime} \mathrm{N}$ and is longitudes $8^{\circ}, 50^{\circ}$ and 11 East. The State is bordered by seven States, Kano and Jigawa to the North, Taraba and Plateau to the South, Gombe and Yobe to the East and Kaduna to the West. Bauchi State has a total of 55 tribal groups in which Hausa, Fulani, Sayawa, Gerawa, Jarawa, kirfawa and Karekare are the main tribes. Bauchi metropolis has a household population of 746, 735 (Bauchi Local Government house to house immunization record, 2018). There are eight (8) wards within the Bauchi metropolis.

\section{Study Design}

This was a cross-sectional investigation that was undertaken within the Bauchi State metropolis between January and November, 2021. The sample size was determined by using the rate of non-responsiveness as a baseline which is between $5-10 \%$ to the HBV vaccine. The sample size was found to be 239 but 352 was collected for convenience with $5 \%$ a level and $99 \%$ strength. The study subjects were from both sexes from age 1 year to 60 years. Out of the 352 subjects, 196 were vaccinated while 156 were unvaccinated. A random sampling technique was employed across all the twelve wards in the Bauchi metropolis. Human research ethical clearance was obtained from the Bauchi State ministry of health human's research ethics committee. A consent form and questionnaire were used to obtain the consent and data from the study subjects relevant to this study respectively.

\section{Study population}

This included individuals living in the Bauchi metropolis who were within the age of 1 year to 60 years. These were individuals, who 
UJMR, Volume 6 Number 2, December, 2021, pp $142-148$

ISSN: 2616 - 0668

had been vaccinated with at least $2^{\text {nd }}, 3^{\text {rd }}$ doses or booster dose of hepatitis $B$ vaccination as prescribed by the State health authority or those who had not been vaccinated and were apparently healthy. In this category of people, only those who consented to participate in this study were considered. However, Individuals who were within the age range of 1year to 60 years but did not consent and those who were not within the age bracket of 1 year to 60 years were excluded from the study.

\section{Collection and Processing of Blood Samples}

A volume of $5 \mathrm{~mL}$ venous blood was aseptically collected in ethylene diamine tetraacetic acid (EDTA) tubes from both the study subjects and the control subjects. The tubes were centrifuged at 2500 revolution per minute (RPM). The plasma was separated and stored at $-21^{\circ} \mathrm{C}$ at the virology laboratories of the infectious diseases Hospital Bayara (IDHB). The plasma was later retrieved to titration of antiHBs levels. The packed red cells were resuspended using $0.9 \%$ normal saline and used for $A B O /$ Rhesus blood grouping.

\section{Determination of $A B O /$ Rhesus Blood Group}

The $A B O$ blood groups $(A, B, O$ and $A B)$

were determined using mouse-derived monoclonal antibodies produced by Ortho Bioclones Diagnostic Systems, Raritan, NJ. The $\mathrm{ABO} /$ Rhesus (Rh) grouping was performed based on conventional methods as described by Kim. et al, (2018). Subjects were classified as; $A B O$ blood groups $A, B, O$ or $A B$ and Rhesus positive $(\mathrm{Rh}+)$ or Rh-negative (Rh-). Four separate drops of a $20 \%$ red blood cell suspension made with $0.9 \%$ normal saline were placed on a plastic tile with four predetermined spots. To 1st drop, 1 volume of anti-A serum was added, to second drop, 1 volume of anti-B was added, while to the 3rd blood drop, 1 volume of anti-D was added and to the fourth blood spot normal saline was added to serve as control. Using a sterile applicator stick, one for each of the drops, the contents were mixed thoroughly. Then the tile was rocked gently for 2 minutes and the result was read by observing for agglutinations. Visible agglutinations in the mixture containing antisera $A, B$, or $A B$ were considered blood group $A, B$ or $A B$ respectively. While visible agglutination in the mixture containing anti-D of any sample was considered Rhesus positive while absence of agglutination was considered Rhesus D negative.

\section{Quantitative detection of Anti-HBs}

The quantitation of the anti-HBs was carried out using a hepatitis B surface antigen Antibody ELISA Kit. The kit was obtained from Abnova Taipei City 114 Taiwan with a lot no: B21110PT. The Hepatitis B surface antigen Ab ELISA Kit is for both qualitative and quantitative detection of antibody to $\mathrm{HBsAg}$ in serum or plasma. The kit utilizes HBsAg on the wells as peroxidase-conjugate which is a solidphase enzyme immunoassay that works based on the "sandwich principle." The assay was carried out according to the manufacturer's instructions.

\section{Statistical analysis}

The statistical analyses were carried out using the statistical package of social sciences (SPSS version 23.0). Computation was made using two-sided $p$ values where $p$ value $<0.05$ was regarded to have statistical significance. Comparisons of the baseline parameters were made using student's t-test and Pearson's v2 test.

\section{RESULTS}

The finding revealed $35(17.9 \%)$ of the vaccinated subjects to be non-responders to the vaccine with no detectable anti-HBs. However, $96(49.0 \%)$ of the vaccinated responded with $\geq 10 \mathrm{IU} / \mathrm{L}$ anti-HBs, 65(33.2\%) had suboptimal anti-HBs response of $<10 \mathrm{IU} / \mathrm{L}$ while among the unvaccinated, 26(16.7\%) had suboptimal anti-HBs of $\leq 10 \mathrm{IU} / \mathrm{L}$. The response of anti- HBs in the vaccinated group was significantly higher compared to the unvaccinated group $(p=0.001)$ as shown in table 1 below. There was no difference in antiHBs protective level in both the participants who had taken two or three doses. On the contrary all the $16(8.2 \%)$ that had been administered booster dose showed anti-HBs titers of $\geq 100 \mathrm{IU} / \mathrm{l}$. These are shown in table 1 . Table 2 shows the association between vaccine immunogenicity and $A B O$ blood group. Blood group $A$ and $O$ had the highest rate of anti-HBs protective level of $52.0 \%$ and $50.8 \%$ respectively. But blood group $B$ had the lowest rate while type $A B$ had $0.00 \%$ rate response to $\mathrm{HBV}$ vaccine. However, there was no statistical significant as regards the association as $\mathrm{P}=$ 0.33 . Similarly, in the non-vaccinated subjects, blood group $A B$ had $100 \%$ anti-HBs protective response followed by Blood group $B$ and $O$ with $27.8 \%$ and $15.2 \%$ respectively. There was equally no significant. 
UJMR, Volume 6 Number 2, December, 2021, pp 142 - $148 \quad$ ISSN: 2616 - 0668

Table 1: Level and distribution of anti-HBs in the vaccinated and non-vaccinated subjects

\begin{tabular}{lcc}
\hline Anti-HBs & Vaccinated $(\%)$ & Non-vaccinated $(\%)$ \\
\hline Protected $(\geq 10)$ & $96(49.0)$ & $26(16.7)$ \\
Not-protected $(\leq 10)$ & $65(33.2)$ & \\
Non-responders & $35(17.9)$ & $156(100.0)$ \\
\hline \multicolumn{1}{c}{ Total } & $196(100.0)$ & \\
\hline
\end{tabular}

Table 2: Anti-HBs immunogenicity among the different blood groups

\begin{tabular}{|c|c|c|c|c|}
\hline \multicolumn{2}{|l|}{ Vaccinated } & \multicolumn{3}{|c|}{ Anti-HBs } \\
\hline ABO blood groups & No. examined & $\geq 10 \mathrm{UI} / \mathrm{L}(\%)$ & $\leq 10 \mathrm{UI} / \mathrm{L}(\%)$ & No response (\%) \\
\hline $\mathrm{A}$ & 25 & $13(52.0)$ & $7(28.0)$ & $5(20.0)$ \\
\hline B & 38 & $17(44.7)$ & $13(34.2)$ & $8(21.1)$ \\
\hline 0 & 130 & $66(50.8)$ & $42(32.3)$ & $22(16.9)$ \\
\hline$A B$ & 3 & $0(0.0)$ & $3(100.0)$ & $0(0.0)$ \\
\hline Total & 196 & $96(49.0)$ & $65(33.2)$ & 35 (17.9) \\
\hline \multicolumn{5}{|c|}{ Statistical analysis: ${ }_{x}^{2}=6.905 ; \mathrm{df}=3 ; \mathrm{p}$-value $=0.33(\mathrm{p}<0.05)-$ not statistically significant } \\
\hline \multicolumn{5}{|c|}{ Non-Vaccinated ABO blood groups } \\
\hline A & 12 & $1(8.3)$ & $0(0.0)$ & \\
\hline B & 18 & $5(27.8)$ & $0(0.0)$ & \\
\hline 0 & 125 & 19(15.2 & $0(0.0)$ & \\
\hline$A B$ & 1 & $1(100.0)$ & $0(0.0)$ & \\
\hline Total & 156 & $26(16.7)$ & $0(0.0)$ & \\
\hline
\end{tabular}

Statistical analysis: ${ }_{x} 2=7.394 ; \mathrm{df}=3 ; \mathrm{p}$-value $=0.06(\mathrm{p}<0.05)-$ not stat. significant

The table 3 below presents the relationships between vaccine response and Rhesus blood group in both the vaccinated and non-vaccinated subjects. Rhesus negative blood group had the highest anti-HBs $\geq 10 \mathrm{UI} / \mathrm{L}$ of $56.3 \%$ while Rhesus positive blood group had
$48.3 \%$ of anti-HBs $\geq 10 \mathrm{UI} / \mathrm{L}$. In the nonvaccinate, $16.9 \%$ of the Rhesus positive had anti-HBs $\geq 10 \mathrm{UI} / \mathrm{L}$ while only 12.5 of Rhesus positive group responded with anti-HBs $\geq 10 \mathrm{UI} / \mathrm{L}$.

Table 3: Distribution of Anti-HBs in the study subjects in relation to Rhesus blood group

\begin{tabular}{llccc}
\hline Vaccinated & & \multicolumn{4}{c}{ Anti-HBs } \\
Rhesus blood groups & No.examined & Anti-HBs $\geq 10 \mathrm{UI} / \mathrm{L}$ & Anti-HBs $<10 \mathrm{UI} / \mathrm{L}$ & No. response $(\%)$ \\
\hline Positive & 180 & $87(48.3)$ & $61(33.9)$ & $32(17.8)$ \\
Negative & 16 & $9(56.3)$ & $4(25.0)$ & $3(18.8)$ \\
Total & 196 & $96(49.0)$ & $65(33.2)$ & $35(17.9)$
\end{tabular}

Statistical result: ${ }_{x} 2=0.546 ; d f=2 ; p$-value $=0.76(p<0.05)-$ not statistically significant Non-Vaccinated Rhesus blood groups

$\begin{array}{lccc}\text { Positive } & 148 & 25(16.9) & 0(0.0) \\ \text { Negative } & 8 & 1(12.5) & 0(0.0) \\ \text { Total } & 156 & 26(16.7) & 0(0.0)\end{array}$

Statistical result: ${ }_{x} 2=0.105 ; \mathrm{df}=1 ; p$-value $=0.75(\mathrm{p}<0.05)$ - not statistically significant

Key: Anti-HBs; antibody to Hepatitis B surface Antigen

\section{DISCUSSION}

This is probably the first study in Bauchi to investigate the association between hepatitis $B$ vaccine immunogenicity with $A B O /$ Rhesus blood group. Our findings indicated a moderate hepatitis B vaccine response of $49 \%$ among the vaccinated study subjects in Bauchi. Hepatitis $B$ vaccine rate of non-responsiveness has been estimated to be $5 \%-15 \%$ globally, (Wiedermann, et al., 2016). This study has shown that $17.9 \%$ ) of the vaccinated subjects to be non-responders which is evidently higher than the estimated level. The finding on the rate of non-responders did not agree with the global estimated levels as it was 3\% higher than the maximum level.
Also, another study has shown that some individuals do not show a protective antiHBs antibody response even after a complete course of primary vaccination (Magaji, et al., 2021). Surprisingly, studies from Rajasthan and Bulgaria showed a higher non-response rate of $30 \%$ and $20 \%$, respectively (Weler and Zeuzem, 2016, Huang, et al, 2013). The rate of non-responders in this study still falls within the average level of the highest rate of nonresponsiveness reported. Similarly, $5-10 \%$ in a given population has been approximately estimated to be suboptimal or poor responders to HBV vaccine (Wiedermann, et al, 2016). This category is believed to produce non-protective anti-HBs $(<10 \mathrm{IU} / \mathrm{L})$ levels (Szmuness, et al, 
UJMR, Volume 6 Number 2, December, 2021, pp 142 - $148 \quad$ ISSN: 2616 - 0668

2018). In this study, $33 \%$ vaccinated subjects had suboptimal or non-protective antibody levels $(<10 \mathrm{IU} / \mathrm{L})$ against HBV. This finding does not agree with the global estimate of poor response to HBV vaccine. However, it agrees with the report of Fuad, et al, (2017) who documented $27.8 \%$ having no protective level against HBV infection in Yemen following vaccination.

The non-vaccinated subjects were incorporated to serve as a control cohort. Ordinarily, anti-HBs should not be found among the unvaccinated, for it is usually produced following inoculation during the vaccine (World Health Organization, 2017). However, it has been established that the same hepatitis $B$ surface antigen ( $\mathrm{HBsAg})$ used as active ingredient in the hepatitis $B$ vaccine has the same infective particle in the hepatitis $B$ components (Mei, et al, 2018). Therefore antiHBs can be present among the non-vaccinated subjects who have been exposed to the HBV. This has been considered to be a result of natural clearance of the viral agents from the host following strong immune response (Olumuyiwa, et al, 2011). This typical scenario was evident as can be seen in table 2 above and 3 below. A total of $26(16.7 \%)$ of the nonvaccinated had $\geq 10 \mathrm{UI} / \mathrm{L}$ anti-HBs level. However, the remaining $130(83.3 \%)$ were considered negative for $\mathrm{HBsAg}$ unlike the vaccinated group that were considered nonresponders.

On the other hand, the rate of protective level of anti-HBs response revealed $49.0 \%$ ) had an HBV protective level of antibody ( $\geq 10 \mathrm{IU} / \mathrm{L}$ ). However, Olumuyiwa, (2011) had earlier in a similar study in Niger State, reported $55 \%$ hepatitis B vaccine response in Niger State Nigeria. This has a wide margin with our present findings. It still did not agree with the finding of Fuad, et al, (2017) who reported $72.2 \%$ to have responded to $\mathrm{HBV}$ vaccine with $\geq$ $10 \mathrm{IU} / \mathrm{L}$ and $27.8 \%$ having no protective antibody against HBV infection in Yemen. In another similar study in subjects within the age bracket of 20-55 years, its findings revealed $96.5 \%$ had protective immunity to hepatitis B, and the anti-HBs response was similar in both male and female, (Abegaz et al., 2021). In another recent study in India, $86 \%$ was reported to have shown good seroconversion in response

REFERENCES

Abegaz, S.B. (2021). Human ABO Blood Groups and Their Associations with DifferentDiseases. BioMed Research International Volume, 66(4) 41-50.

Adebola, T., O., Akin, O., Muhammad, S., Balogun, A., A., Patrick, N., Moses, A., Abiodun, E. O., Simeon, W. A., to the Hepatitis B vaccine, while $10 \%$ were suboptimal responders, (Yang, 2019). It seems geographical locations and $\mathrm{ABO} /$ Rhesus factors may partly account for the heterogeneity of the immune response, as the highest rate of response seems to come from the same region. On the association of the responsiveness with the $A B O /$ Rhesus type, type $A$ and $O$ had higher levels of anti-HBs protective level and compared to other blood types (Berinyuy et al., 2019). However, there was no statistical significance.

\section{CONCLUSION}

This study indicated blood group 0 and Rhesus positive blood group had the highest rate of hepatitis B vaccine failure, compared with other blood groups and Rhesus factor. This is an indication that some blood group and Rhesus factors do not have affinity to hepatitis B vaccine response. In addition, $16 \%$ of the unvaccinated were found to have $\geq 10 \mathrm{UI} / \mathrm{L}$ antiHBs levels of which most of them were of blood group $\mathrm{O}$ and Rhesus Positive blood. However, there was no statistical significance. Therefore, it seems blood group $\mathrm{O}$ and Rhesus Positive subjects have the ability to produce protective anti-HBs following exposure to hepatitis B virus. There is a need for more investigation on the association between $\mathrm{ABO} /$ Rhesus and HBV vaccine failure, especially the chemistry of the blood.

Contribution to Knowledge: the study revealed that some blood groups and Rhesus factors respond to hepatitis $B$ vaccine more than others.

Conflict of interest: None declared

Acknowledgements: the authors wish to appreciate all who helped with sample collection, laboratory testing, and data analysis; Mispha Thomas, Benedict Pwol, IkpaVicent, Moses Menegbe and Victoria Sumi. We also acknowledge all the vaccinated and unvaccinated subjects who participated in this very study.

Authors' contributions: Patricia, M. Lar, Zakari Hashimu, and Mrs. Tabitha Vem Silas critically reviewed the manuscript for intellectual content; Kyauta Mallam Thomas contributed to the study designs and conducted the laboratory investigations and the statistical analysis

Samuel, S., Bolanle, O. P., Musa, S. and Abdulsalami, N. (2016). Seroprevalence of Hepatitis B Infection in Nigeria: A National Survey. AmericanJournal of Tropical Medical Hygiene, 95(4), 902907. 
UJMR, Volume 6 Number 2, December, 2021, pp 142 - $148 \quad$ ISSN: 2616 - 0668

Bauchi Local Government Area. (2018). House to house immunization record. National Programme on Immunization, 12-34.

Berinyuy, B. E., Alawode R Adenike, Mohammed Alkali Bala, Babalola B Shukurat, et al. (2019). Prevalence of Hepatitis B Virus in Nigeria: Review Update. Annal Pub Health and Epidemiology, 1(1), 1-7.

Blumberg BS. (1977). Australia antigen and the biology of hepatitis B. Science, 19(7), 17-25.

Casanova, JL. (2015). Human genetic basis of inter-individual variability in the course ofinfection. National Academy of Sciences, 112(51); 127-138.

Cooling, L. (2015). Blood groups in infection and host susceptibility. Clin. Microbiol Review,2(8), 801-870..

Damulak, OD., Ogbenna V., Ma'an O., Rufai SD., Kut T., Bodund A. (2013). Hepatitis $B$ virus sero-positivity among voluntary blood donors at a centralized blood service centre in Nigeria. International Journal of Medical and Applied Sciences 2(3), 10-18.

Fan, Q, Zhang, W, Li, B, Li, D-J, Zhang, J and Zhao, F. (2020). Association Between ABOBlood Group System and COVID-19 Susceptibility in Wuhan. Front. Cell. Infect.Microbiol.10:404.

Fuad, AAA.,Naila, AA., Fawzi, A., Nader., SA., Mohammed SA., Tari, G., BH and Atif $A E,(2017)$. Assessment of Immunization to Hepatitis Vaccine among Children under Five Years in Rural Areas of Taiz, Yemen Hepatitis Research and Treatment, 21(3), 1-37.

Expanded programme on immunization (1992). Global Advisory Group Part I. Weekly Epidemiol Rec., 67: 11-5.

Graber-Stiehi, I, (2018). The silent epidemic killing more people than HIV, malaria, TB.Nature and Science, 564(734), 24-7.

Gunasekaran, J and Sree, PN, (2018).Prevalence of NonResponsiveness to an Indigenous Recombinant Hepatitis B Vaccine: A Study among Health Care Workers in a Tertiary Hospital.International Journal for Modern Trends in Science and Technology, 7(6), 10- 16.

Huang, YH, Hsiao LT, Hong YC, et al. (2013). Randomized controlled trial of entecavir prophylaxis for rituximab associated hepatitis $B$ virus reactivation in patients with lymphoma and resolved hepatitis B. J Clin Oncology, 31(22):2765-72.

James, A. N., Obinna ON, Georgebest ON, Echeonwu SAJ, Onyeka, A., et al.
(2012). Studies on Prevalence and

Risk Factors for Hepatitis B Surface Antigen among Secondary School Students in North-central, Nigeria. Sierra Leone Journal of Biomedical Research, 3(3): 163-168.

Kim, JH, Kim, YD, Lee, M, et al. (2018). Modified PAGE-B score predicts the risk of hepatocellular carcinoma in Asians with chronic hepatitis B on antiviral therapy. J Hepatology, 69(5):10661073.

Magaji, F.A., Okolo, M.O., Yiltok, E.S., Golt, W., Anzaku, S.A., Ogwuche, J.,Pam, V.C., Ocheke, A.N., Musa, J., Isichie, C., Imade, G.E., Mutihir, J.T., Ugwu, B.T., Agbaji, O., $\quad$ Sagay, S.A., Zoakanh, A.I and Chn, S.E. (2021). Prevalence of Hepatitis B virus Infection in Pregnant Women with and Without HIV in Jos, Nigeria.

International Journal of Infectious Diseases, 10(4): 276-281.

Mei Sun, Chengyue, Li., Dan, Wu, Pingping, Li Jun Lu, Ying Wang Fengshui Chang,, Xiaohong Li, and, Mo, H. (2018). Impact Evaluation of the Routine Hepatitis B Vaccination Program of Infants in China. Journal of Public Health, 41(1); 158-163.

National Population Commission. (2006). Nigeria National Population Census. Federal Ministry of Information and Culture Data Population, 23.

Qin, Y and Liao, P. (2018). Hepatitis B virus vaccine breakthrough infection: surveillance of Sgene mutants of HBV. Actavirologica, 6(2), 115-121.

Olumuyiwa, 0. Odusanya Ewan Alufohai, Francois, P. Meurice and Vincent, I.A. (2011). Five year Post Vaccination Efficacy of Hepatitis B Vaccine in rural Nigeria. Human Vaccines, 7(6), 625-629.

Perrillo, RP, Gish, R., Falck-Ytter, YT. (2015). American Gastroenterological AssociationInstitute technical review on prevention and treatment of hepatitis B virus reactivation during immunosuppressive drug therapy. Gastroenterology, 148(1), 221-244.

Sadoh, AE and Ofili, A. (2014). Hepatitis B infection among Nigerian children admitted to a children's emergency room. African Health sciences, 1(4), 377-385.

Szmuness, W., Stevens, CE.,Zang, EA., Harley, EJ and Kellner, A.A. (2018). Controlled Clinical Trial of the Efficacy of the Hepatitis B vaccine (Heptavax B): A final report. Hepatology, 1, 377-385. 
UJMR, Volume 6 Number 2, December, 2021, pp 142 - $148 \quad$ ISSN: 2616 - 0668

Wang, De-Shen, Chen, DL., Ren, C., Wang, Zhi-

Qiang Wang, Miao-Zhen Qiu, MZ., Luo, HY., Dong-Sheng Zhang, Feng-

Hua Wang, Li, YH and Xu, RH. (2012). ABO blood group, hepatitis $B$ viral infection and risk of pancreatic cancer. International Journal of Cancer,131, 461-468.

Welker, MW.,Zeuzem, S. (2016). Pre- and posttransplant antiviral therapy (HBV, HCV). Visc Med. 32(2), 105- 109.

Wiedermann, U., Garner-Spitzer, E and Wagner, A. (2016). Primary Vaccine Failure to Routine Vaccines: Why and what to do? Human Vaccine and Immunotherapeutic, 12(1), 239-243.

World Health Organization. (2016). WHO Global health sector strategy on viral hepatitis 20162021: towards ending viral hepatitis. Geneva: Available at:apps.who.int/iris/bitstream/10665/2 46177/1/WHO HIV 2016.06-

eng.pdf. (Last accessed 25 February 2017.
World Health Organization. (2017). Hepatitis B fact sheets no 204. Available at:http://www. who.int/mediacentre/f actsheets/fs204/en Accessed 16th January 2012.

Xu, W., Yu, J., Wong, VW. (2017). Mechanism and prediction of HCC development in HBV infection. Best Pract Res Clin Gastroenterology, 31(3), 291-298.

Yang, L., Liu, F., Tong, X., Hoffmann, D., Zuo, $J$ \& Lu, M. (2019). Treatment of Chronic Hepatitis B Virus Infection Using Small Molecule Modulators of Nucleocapsid Assembly: Recent Advances and Perspectives. ACS Infect. Dis. 5, 713724.

Zenebe, Y, Muku, W, Yimer MM, Abera B, (2014). Seroprevalence and risk factors of hepatitis B virus and human immunodeficiency virus infection among pregnant women in Bahir Dar city, Northern Ethiopia: a cross sectional study. Infectious Diseases, 14: 118. 